\title{
The Significance of Family History Status in Relation to Neuropsychological Test Performance and Cerebral Glucose Metabolism Studied with Positron Emission Tomography in Older Alcoholic Patients
}

Kenneth M. Adams, Sid Gilman, Doug Johnson-Greene, Robert A. Koeppe, Larry Junck, Karen J. Kluin, Susan Martorello, Michael J. Johnson, Mary Heumann, and Elizabeth Hill

Patients with severe chronic alcoholism have decreased rates of glucose metabolism in the medial frontal lobe and correlated abnormalities of neuropsychological functioning. The potential influence of family history of alcoholism has not been examined in these patients. In a retrospective study, we used neuropsychological tests and neuroimaging employing $\left[{ }^{18} \mathrm{~F}\right]$ fluorodeoxyglucose with positron emission tomography to study $\mathbf{4 8}$ older subjects who had histories of severe, chronic alcohol dependence. These patients were divided into two groups: 27 with a first-degree relative with chronic alcoholism and 21 patients without first-degree relative with chronic alcoholism. No differences were found between groups on either neuropsychological or neuroimaging tests. These results suggest that a family history of alcoholism does not moderate the damaging effects of severe chronic alcoholism on the functioning of the medial frontal lobe.

Key Words: Alcoholism, Family History, Neuropsychological Tests, Neuroimaging, Positron Emission Tomography.

$\mathbf{P}$ ATIENTS WITH chronic alcohol dependence frequently have family members with histories of alcohol abuse or alcohol dependence. ${ }^{1,2}$ Often, these family members are first-degree relatives (i.e., father, mother, or sibling). There is an estimated 7 -fold increase of risk for alcoholism in people with a first-degree relative with a diagnosis of alcohol dependence. ${ }^{3,4}$

The increased risk of developing alcoholism in people with relatives who have diagnoses of alcoholism has prompted investigators to determine whether those at risk have central nervous system abnormalities that might predate the development of the disorder. The offspring of

From the Psychology Senvice (K.M.A., D.J.-G., M.J.J.), Ann Arbor Veteran's Affairs Medical Center, Departments of Neurology (S.G., D.J.-G., L.J., K.J.K., S.M., M.H.), Psychiaty (K.M.A.), Intemal Medicine (Division of Nuclear Medicine) (R.A.K), and Physical Medicine and Rehabilitation (K.I.K.), University of Michigan; and the University of Michigan Alcohol Research Center (K.M.A., S.G., D.J.-G., K.J.K., L.J., E.H., S.M.), Ann Arbor, MI.

Received for publication October 16, 1996; accepted September 5, 1997 This study was supported by the National Institute on Alcoholism and Alcohol Abuse (P50 AA 07378), as well as by the National Institutes of Health Grants N15655 and $A G 08671$ and a sharing agreement for PET between the Department of Veterans Affairs and the University of Michigan.

Reprint requests: Kenneth M. Adams, Ph.D., Chief, Psychology Service (116B), Veterans Affairs Medical Center, 2215 Fuller Road, Ann Arbor, MI.

Copyright $(1098$ by The Research Society on Alcoholism. chronic alcoholics are reported to show abnormal neurological test findings, such as altered electrophysiological potentials ${ }^{5}$ and cognitive dysfunction, ${ }^{6}$ even in the absence of alcohol abuse or dependence. It has also been asserted that first-degree relatives of alcoholic patients-and especially sons of alcoholic fathers-have poorer neuropsychological test results when compared with normal control subjects. $^{7-11}$ Other studies have reported no differences between sons of alcoholic patients and control subjects. ${ }^{12,13}$ Thus, the results of these studies have not yielded a consistent picture of neurological or neuropsychological abnormality in first-degree relatives of alcoholics.

Alcoholic patients have abnormal local cerebral metabolic rates for glucose (lCMRglc) as measured by positron emission tomography (PET).$^{14,15}$ Previous studies of 1CMRglc with PET in chronic alcoholic patients have not examined the issue of family history. Small subgroups of patients with and without positive family histories have been mentioned briefly in other investigations of the effects of chronic alcoholism using neuroimaging. Mampunza and associates ${ }^{16}$ found a greater frequency of abnormalities of cerebral blood flow measured with [ $\left.{ }^{99 \mathrm{~m}} \mathrm{Tc}\right] \mathrm{HMPAO}$ and single photon emission-computed tomography (SPECT) in patients who reported a history of drinking problems in their relatives than those who did not. Another study examining family history association with $\left[{ }^{99 \mathrm{~m}} \mathrm{Tc}\right] \mathrm{HMPAO}-$ SPECT results, however, revealed no relationship. ${ }^{17}$ In studies with $\left[{ }^{18}\right.$ F]2-deoxy-2-fluoro-D-glucose (FDG) and PET, Volkow and colleagues ${ }^{18}$ found that subjects with a family history of alcoholism showed lowered cerebellar lCMRglc at rest and blunted response to a dose of $30 \mu \mathrm{g} / \mathrm{kg}$ lorazepam when compared with subjects with no family history of alcoholism. Few studies on alcoholism using neuroimaging have included other domains, such as neuropsychological measures of cognitive functioning.

In the present study, both neuropsychological and neuroimaging data were examined in patients who underwent neuropsychological evaluation and received FDG with PET scanning. The goal was to determine whether or not there was a relationship between family history status, neuropsychological, and neuroimaging results. We hypothesized that 
Table 1. Means (M) and Standard Deviations (SD) for Demographic Characteristics of Subjects with FDRs and Subjects with NFDRs

\begin{tabular}{|c|c|c|}
\hline \multirow[b]{2}{*}{ Variable } & \multicolumn{2}{|c|}{ Group } \\
\hline & $\begin{array}{c}\text { FDRs } \\
(n=27)\end{array}$ & $\begin{array}{l}\text { NFDRs } \\
(n=21)\end{array}$ \\
\hline \multirow[t]{2}{*}{ Age in years* } & $M-46.3$ & $M-52.4$ \\
\hline & $S D-8.9$ & $S D-6.9$ \\
\hline \multirow[t]{2}{*}{ Education in years } & $M-12.5$ & $M-12.5$ \\
\hline & $\mathrm{SD}-2.1$ & $S D-1.5$ \\
\hline \multirow{2}{*}{$\begin{array}{l}\text { Wechsier Adult Intelligence Scale-Revised } \\
\text { Fult-Scale IQ }\end{array}$} & $M-97.7$ & $M-99.1$ \\
\hline & $S D-8.2$ & $S D-10.7$ \\
\hline \multirow[t]{2}{*}{ Years of heavy drinking } & $M-18.6$ & $M-20.6$ \\
\hline & SD-9.1 & SD- -9.2 \\
\hline \multirow{2}{*}{$\begin{array}{l}\text { Lifetime estimated alcohol consumption } \\
\qquad \text { (kg ethanol) }\end{array}$} & $M-860$ & $M-1115$ \\
\hline & $S D-458$ & $S D-781$ \\
\hline
\end{tabular}

${ }^{*} p<0.05$

alcoholic subjects with a first-degree family member having alcoholism would show greater neuropsychological impairment than alcoholic subjects without a first-degree relative with a history of alcoholism. We also hypothesized that PET measures of metabolic functioning would show reduced rates of metabolic activity in subjects having firstdegree family relatives with alcoholism.

\section{METHODS}

\section{Subjects}

Before entrance into this study, 48 male chronic alcoholic patients were recruited from the Alcohol Treatment Unit and the Outpatient Clinics of the Ann Arbor Veterans Affairs Medical Center. Subjects were selected from patients with established histories of severe chronic alcoholism if they met the criteria described herein. Subjects were interviewed to determine both individual and family histories of substance abuse and to complete the Diagnostic Interview Schedule (DIS) ${ }^{19}$

Family history of alcoholism was assessed during interviews with the participant. A pedigree protocol was constructed showing children, parents, siblings, aunts, uncles, and grandparents. For each relative, the level of alcohol use was assigned (abstinent, social drinker, probable, or definite alcoholism). Alcoholism was coded using criteria from the Family Informant Schedule and Criteria (FISC) ${ }^{20}$ Probable alcoholism was coded if the respondent could give examples of the relative being frequently drunk, drinking regularly and heavily, or "always has a glass in his/her hand." Definite alcoholism was coded if the respondent could also name a specific consequence from the FISC list (legal, marital, work, or health problems, fights while drunk, or alcoholism treatment). In the present study, "probable" and "definite" codes were collapsed.

Through comprehensive interviews, the subjects were characterized as having either: (1) a first-degree relative (parent or sibling) or a first- and second-degree relative (aunt, uncle, cousin, or grandparent) who were coded as alcoholic; or (2) no first-degree, but only a second-degree relative, or no family history coded for alcoholism. There were 27 patients with a first-degree alcoholic relative (FDR) or both a first- and seconddegree relative, and 21 patients with no first-degree alcoholic relative (NFDR). The demographic characteristics of these two groups are shown in Table 1. Statistically significant differences were found between FDR and NFDR subjects in terms of age.

All patients underwent neuropsychological examinations and met the diagnostic criteria for alcohol dependence as defined in DSM-IV. ${ }^{1}$ In the present study, only 3 of the 48 subjects were identified as having antisocial personality disorder by DIS ${ }^{19}$ results. All but one of the patients exceeded a weekly intake of at least $560 \mathrm{~g}$ of ethanol over 2 of the 3 preceding years. The patients substantially exceeded the $560 \mathrm{~g}$ level for an average of 19 years at the time of the study. All of the patients had at least one hospitalization for alcoholism, and 34 of the 48 patients had achieved sobriety for 1 month or more at some earlier point in their drinking history, but had relapsed. These data characterize the patients as "heavy" drinkers in both duration and intensity of alcohol intake. ${ }^{21}$

Patients were selected to exclude those with a history of polydrug abuse. We used the following quantitative criteria to define abuse by the National Institute on Drug Abuse in the National Collaborative Study of Polydrug Abuse ${ }^{22}$ : (1) no recreational injection of any drug at any time; (2) no more than six uses of marijuana in the year preceding entry to the study; (3) no more than 20 total occasions of hallucinogen use (including PCP); (4) no more than five noninjectable uses of heroin/opium in the preceding year; (5) no more than 100 pills, tablets, or capsules of synthetic narcotics in the preceding year; (6) no more than 15 nonpharmaceutical uses of amphetamines or cocaine ever; (7) no more than 90 uses of pharmaceutical amphetamines or methylphenidate; (8) no more than 30 (nonprescription) uses of minor tranquilizers (e.g., diazepam and chlordiazepoxide) in the year preceding testing; (9) no more than 60 (nonprescription) uses of sedative hypnotics in the year before study; and (10) no other use of exotic chemical comforts (e.g., amyl nitrate). Other exclusion criteria included neurological disorders unrelated to alcohol abuse, including closed head injury with loss of consciousness $>30$ min, stroke, birth complications, learning disorders, and other acquired or developmental disease associated with increased risk for neuropsychological impairment in previous studies of alcoholic patients. ${ }^{2.3}$

Patients were studied subsequent to discharge from an inpatient alcohol treatment unit after a mean abstinence of 31 days. The minimum period of abstinence was 14 days in the case of only one subject, and the median was 44 days. Some had a clinical history of malnutrition, but had been provided with standard hospital diet and multivitamin therapy since admission to the hospital. A dietitian reviewed the patients' nutrition, and all patients studied had been consuming a normal diet for at least 2 weeks before study. Blood and urine examinations performed within 7 days of the PET scan showed no evidence of ketosis or abnormal glucose levels. During the period of study, the patients were taking no medications known to affect the central nervous system, other than disulfiram. One subject in the FDR group and six subjects in the NFDR group were taking disulfiram at the time of the study in the standard $250 \mathrm{mg}$ daily dose.

\section{Neuropsychological Testing}

Neuropsychological examinations were performed by an experienced neuropsychologist. The examinations took place in a quiet, dedicated laboratory near the patients' hospital unit. Each patient completed a protocol consisting of the Wechsler Adult Intelligence Scale-Revised, and a modified and extended Halstead-Reitan Neuropsychology Test Battery. ${ }^{24}$ Data from the examinations are comparable with normative standards based on an extensive program of testing in normal subjects, obviating the need to test control subjects.

\section{PET}

PET studies were standardized for all subjects. The subjects were fasted for $4 \mathrm{hr}$ before the scan, and studied lying supine and awake in a quiet room, alert but not speaking, with eyes open from $5 \mathrm{~min}$ before injection until completion of the scan. A catheter was placed in a radial artery for blood sampling. PET studies were performed after intravenous injection of $10 \mathrm{mCi}$ of FDG.

Subjects were imaged with either a Siemens/CTI 931/08-12 or a Siemens ECAT EXACT-47 scanner. Images from both scanners were reconstructed to a resolution of 8 to $9 \mathrm{~mm}$ full-width at half-maximum in-plane. Because the axial sampling of the EXACT-47 scanner is twice as fine as that of the 931, two adjacent levels from the EXACT were averaged, providing images with the same axial spacing and nearly the same resolution as the 931 scanner. Data were acquired with the Siemens/ 
Table 2. Means (M) and Standard Deviations (SO) of Neuropsychological Test Performances for Alcoholic Subjects with FDRs and Subjects with NFDRs

\begin{tabular}{|c|c|c|}
\hline \multirow[b]{2}{*}{ Variable } & \multicolumn{2}{|c|}{ Group } \\
\hline & $\begin{array}{l}\text { FDRs } \\
(n=27)\end{array}$ & $\begin{array}{l}\text { NFDRs } \\
(n=21)\end{array}$ \\
\hline Halstead Impairment Index & $\begin{array}{l}M-0.51 \\
S D-0.27\end{array}$ & $\begin{array}{l}M-0.53 \\
S D-0.27\end{array}$ \\
\hline $\begin{array}{l}\text { Tactual Performance Test } \\
\text { (Time/block-T score) }\end{array}$ & $\begin{array}{l}M-47.3 \\
S D-10.9\end{array}$ & $\begin{array}{l}M-45.6 \\
S D-9.2\end{array}$ \\
\hline $\begin{array}{l}\text { Tactual Performance Test } \\
\text { (Memory } T \text {-score) }\end{array}$ & $\begin{array}{l}M-47.0 \\
S D-11.9\end{array}$ & $\begin{array}{l}M-47.4 \\
S D-9.3\end{array}$ \\
\hline $\begin{array}{l}\text { Tactual Performance Test } \\
\text { (Location } T \text {-score) }\end{array}$ & $\begin{array}{l}M-47.7 \\
S D-10.1\end{array}$ & $\begin{array}{l}M-50.0 \\
S D-7.9\end{array}$ \\
\hline $\begin{array}{l}\text { Speech-Sounds Perception Test } \\
\text { (Errors } T \text {-score) }\end{array}$ & $\begin{array}{l}M-39.8 \\
S D-9.9\end{array}$ & $\begin{array}{l}M-42.2 \\
S D-8.9\end{array}$ \\
\hline $\begin{array}{l}\text { Seashore Rhythm Test } \\
\text { (Correct } T \text {-score) }\end{array}$ & $\begin{array}{l}M-50.0 \\
S D-13.1\end{array}$ & $\begin{array}{l}M-53.6 \\
S D-8.9\end{array}$ \\
\hline $\begin{array}{l}\text { Halstead Category Test } \\
\text { (Errors T-score) }\end{array}$ & $\begin{array}{l}M-40.4 \\
S D-10.6\end{array}$ & $\begin{array}{l}M-42.1 \\
S D-10.1\end{array}$ \\
\hline $\begin{array}{l}\text { Finger Tapping } \\
\text { (Dominant } T \text {-score) }\end{array}$ & $\begin{array}{l}M-44.5 \\
S D-12.4\end{array}$ & $\begin{array}{l}M-46.8 \\
S D-17.1\end{array}$ \\
\hline
\end{tabular}

CTI 931/08-12 scanner as two interleaved image sets. Attenuation correction was calculated by the standard ellipse method.

Data were acquired 30 to 90 min postinjection and quantified using the static scan method of Hutchins et al. ${ }^{25}$ Blood samples were taken as rapidly as possible during the first 2 min after tracer injection and then at progressively longer intervals throughout the remainder of the study. A total of 25 to 30 samples/scan was analyzed. The samples were centrifuged, and the plasma radioisotope concentrations were measured in an $\mathrm{NaI}$ well counter.

Data from the PET studies were mapped into a standard stereotactic orientation using an automated method for rotational and translational transformation, ${ }^{26}$ followed by linear scaling and nonlinear warping of individual brains. ${ }^{27} \mathrm{We}$ obtained volumes of interest (VOIs) acquired from the anterior to posterior extent of the brain bilaterally. In particular, we focused on three stereotactically defined regions of the frontal cortex bilaterally (medial, dorsolateral, and orbitomedial) because abnormalities of ICMRglc have been found in the medial aspects of the frontal cortex of patients with severe chronic alcoholism, ${ }^{28}$ and correlations have also been demonstrated between these three regions and performance on neuropsychological tests of executive function. ${ }^{29}$ We used other VOIs (posterior temporal, inferior parietal, and cerebellum) as comparison regions for analysis.

\section{RESULTS}

The means and standard deviations of the key neuropsychological variables for the two subject groups are reported in Table 2. Although the overall level of neuropsychological impairment seemed to be moderate in both groups of subjects (cf. Halstead Impairment Index), there was no difference in mean performance level of these groups. An overall multivariate analysis of the neuropsychological variables revealed no significant difference between the groups [Hotellings $T^{2}(S=1, M=31 / 2, N=171 / 2), 0.13$, df $(9,37)$, $p=0.85]$. Because the degree of variability in alcohol
Table 3. Comparison of ICMRgle (Mean \pm SD Averaged Between Hemispheres) for Subjects with FDRs and Subjects with NFDRs

\begin{tabular}{|c|c|c|}
\hline Structure & $\begin{array}{c}\text { FDRs } \\
(n=27)\end{array}$ & $\begin{array}{c}\text { NFDRs } \\
(n=21)\end{array}$ \\
\hline Cingulate average frontal & $6.3 \pm 0.95$ & $6.3 \pm 1.0$ \\
\hline Dorsolateral average frontal & $6.6 \pm 0.89$ & $6.4 \pm 0.99$ \\
\hline $\begin{array}{l}\text { Orbitomedial average } \\
\text { frontal }\end{array}$ & $5.6 \pm 0.69$ & $5.5 \pm 0.85$ \\
\hline $\begin{array}{l}\text { Posterior temporal lobe } \\
\text { average }\end{array}$ & $6.8 \pm 0.87$ & $6.8 \pm 1.0$ \\
\hline Cerebellum average & $5.2 \pm 0.78$ & $5.0 \pm 0.62$ \\
\hline Inferior parietal average & $6.6 \pm 0.93$ & $6.5 \pm 1.0$ \\
\hline Whole brain cerebral cortex & $4.9 \pm 0.8$ & $4.9 \pm 0.71$ \\
\hline
\end{tabular}

Table 4. Comparison of ICMRglc (Mean \pm SD Averaged Between Hemispheres) Normalized to Whole Brain Cortex for Alcoholic Subjects with FDRs and Subjects with NFDRs

\begin{tabular}{lcc}
\multicolumn{1}{c}{ Structure } & $\begin{array}{c}\text { FDR } \\
(n=27)\end{array}$ & $\begin{array}{c}\text { NFDR } \\
(n=21)\end{array}$ \\
\hline $\begin{array}{l}\text { Cingulate average frontal } \\
\text { Dorsolateral average frontal }\end{array}$ & $1.3 \pm 0.08$ & $1.3 \pm 0.07$ \\
$\quad \begin{array}{l}\text { Orbitomedial average } \\
\quad \text { frontal }\end{array}$ & $1.3 \pm 0.05$ & $1.3 \pm 0.06$ \\
$\quad \begin{array}{l}\text { Posterior temporal tobe } \\
\quad \text { average }\end{array}$ & $1.4 \pm 0.06$ & $1.1 \pm 0.07$ \\
$\quad \begin{array}{l}\text { Cerebellum average } \\
\text { Inferior parietal }\end{array}$ & $1.0 \pm 0.12$ & $1.4 \pm 0.08$ \\
& $1.3 \pm 0.06$ & $1.0 \pm 0.13$ \\
\end{tabular}

intake was so great, especially in the NFDR group (Table 1 ), we used the years of heavy drinking reported by the subject as a covariate to adjust within-cell estimates. This was not an attempt to use the covariance technique to ameliorate differences between the groups, but rather to increase the precision of the regression within the parameters of the analysis of variance. ${ }^{30,31} \mathrm{~A}$ second multivariate $T^{2}$ test using years of heavy drinking as a covariate produced no difference between the groups [Hotellings $T^{2}$ $(S=1, M=31 / 2, N=16), 0.12, d f(9,34), p=0.90]$.

The PET results for absolute and normalized ICMRglc from regions of interest selected on an a priori basis are shown in Tables 3 and 4 , respectively.

A similar analysis was conducted using family history as an independent variable, years of heavy drinking as a covariate, and the ICMRglc values for various brain regions from the PET scan as dependent variables. Both absolute and normalized ICMRglc values were tested. Overall. MANOVA results were not significant for either absolute [Hotellings $T^{2}(S=1, M=21 / 2, N=171 / 2), 0.08, d f(7,37)$, $p=0.89$ ] or normalized [Hotellings $T^{2}(S=1, M=2, N=$ $18), 0.06, d f(6,38), p=0.87$ ] ICMRglc PET values.

With samples of $\sim 25$ subjects/group, we have power of $\sim 0.80$ to detect effect sizes of $0.80\left(\left[X_{1}-X_{2} / \partial\right]\right)$. Groups were virtually identical on most measures. No differences were observed in this study that reached even $0.3 \mathrm{mg} / 100$ $\mathrm{g} / \mathrm{min}$ for absolute data, and even less for normalized data. Such small differences require $\sim 180$ subjects/group to produce any group divergence, which in any event would not be clinically significant. 


\section{DISCUSSION}

The results of this study suggest that, for patients with chronic severe alcoholism, having a first-degree family member with a diagnosis of alcoholism is not associated with worse neuropsychological test performance or reduced lCMRglc, compared with highly similar patients without a first-degree relative with a diagnosis of alcoholism. Impairment measured neuropsychologically in both groups is likely related to the severe level of chronic alcoholism in both groups of subjects.

Current evidence cited in the introduction of this study suggests that, for younger patients, ${ }^{5,6}$ a family history of alcoholism may increase the risk for central nervous system impairment from alcoholism. This would imply, for those at increased risk, an earlier emergence of deleterious central nervous system effects associated with prolonged and uncontrolled drinking.

The present results add data to the older end of the developmental spectrum in chronic and severe alcoholic patients. We did not observe differences in neuropsychological or neuroimaging variables in these carefully selected subjects who differed only in family history and mean age by 6 years. However, we cannot rule out the possibility that, in terms of impairment, patients without increased risk associated with a positive family history may have "caught up" to those having increased vulnerability at an early age. Because we did not have the opportunity to assess these patients earlier in their alcoholism, this remains speculative. A study of older alcoholic patients with less severe histories and fewer years of heavy drinking might possibly reveal an association of family history with neuropsychological and neuroimaging results.

In the present study, our "negative" NFDR family history group was slight older, although there is no information or data to suggest that neuropsychological or metabolic differences could be ascribed to such an age difference of 6 years. Total alcohol intake and years of heavy drinking were also numerically greater in the NFDR, but not statistically significant.

Nonetheless, in this study, neuropsychological assessment with tests sensitive to dysfunction in problem solving and executive skills (e.g., problem solving, rule learning, concept formation, and set shifting) reveal the behavioral impairment in these subjects. The deficits in executive skills obtained even though these subjects were abstinent from alcohol for at least 30 days at the time of study and were medically stable. ${ }^{28,29}$ These results are consistent with previous work identifying the additive effects model of age and alcoholism as co-factors in producing neuropsychological impairment. $^{32}$

The ICMRglc data from the PET scans also have a link to previous work from both our laboratory and those of others. ${ }^{33-37}$ Converging data point to certain regions in the frontal lobe as being selectively vulnerable to the effects of alcohol, perhaps added to effects of aging and cerebral atrophy. The present data do not provide confirmation that those subjects with first-degree family relatives with alcoholism will sustain greater cerebral damage than those without such histories later in their lives. The present $\mathrm{lC}$ MRglc data from the PET scans obviously pertain to brain state at rest, which is likely to be the most reproducible kind of finding; but, activation paradigms with challenge to the brain might shed additional light on this question.

We should note that we did not construct formal genetic pedigrees as a basis for our family history groupings for subjects. Our method involved survey of available family members, but did not rise to the level of an exhaustive reconnaissance characteristic of true family history studies. At the same time, the relatively simplicity of our criteria serve to make our group definition nominal and statistically conservative. Continuous parameters reflecting relative genetic risk are likely less reliable and have more inherent measurement error than more binary renderings of genetic risk, however gross.

Further, the establishment of what may constitute a "positive" or "negative" family history of alcoholism is controversial in and of itself..$^{38}$ Family study methods involve direct interviews of all family members. Family history methods are those that collect diagnostic information about all family members by interviewing one or several informants per family. Some data suggest that the accuracy of family history methods is higher for the diagnoses of major depression or alcoholism than for other psychiatric diagnoses, such as phobia, anxiety disorder, and other entities. ${ }^{39}$ The family history method itself is limited by results that are high in specificity, but low in sensitivity. ${ }^{39,40}$ However, accuracy of the family history method for alcoholism is sufficiently high so as to be "the method of choice" in investigations where familiality is hypothesized, but research does not yet justify the expense of the family study method to examine the details of familial transmission. ${ }^{2}$

The presence of certain developmental influences, such as a difficult childhood, have a further additive effect with family history of alcoholism and suggest that other phenotypic factors are likely to moderate genetic risk. ${ }^{41}$

There is also some question as to whether family history alone is a sufficient marker for increased risk. Factors such as the presence of antisocial personality, in addition to family history, might strengthen the prediction of vulnerability to chronic alcoholism. In this conceptualization, persons at greater risk would demonstrate a greater incidence of cognitive impairment that would emerge as a function of age and uncontrolled consumption of alcohol. ${ }^{42}$

A more complex, but more adequate, explanation might be drawn from an extension that has been postulated as "brain reserve theory" by Satz. ${ }^{43}$ In this threshold-type conceptualization, there would be differing liabilities that genetic risk, disease exposure, and environmental or phenotypic parameters might each contribute to any given individual's likelihood of showing evidence of brain-behavior impairment. In longitudinal or "follow-back" retrospec- 
tive studies with adequate data, this theory could be tested directly.

Finally, we should emphasize that, whereas the groups studied herein are numerically large for a PET study and have sufficient power to test our hypotheses, the study design is a retrospective one that is associational as contrasted with an experimental one. This distinction precludes any cause-and-effect statements about family history in relation to neuropsychological and neuroimaging variables.

\section{REFERENCES}

1. American Psychiatric Association: Diagnostic and Statistical Manual of Mental Disorders, ed 4. Washington, D.C., American Psychiatric Association, 1994, p 203

2. Tsuang MT, Tohen M, Zahner GE: Textbook in Psychiatric Epidemiology. New York, John Wiley, 1995, p 356

3. Merikangas KR, Leckman JF, Prusoff BA, Pauls DL, Weissman MM: Familial transmission of depression and alcoholism. Arch Gen Psychiatry 42:367-372, 1985

4. Merikangas KR: The genetic epidemiology of alcoholism. Psychol Med 20:11-22, 1990

5. Porjesz B, Begleiter H: Event-related potentials and cognitive function in alcoholism. Alcohol Health Res World 19:108-112, 1995

6. Pihl RO, Bruce KR: Cognitive impairment in children of alcoholics. Alcohol Health Res World 19:142-147, 1995

7. Goodwin D: Familial alcoholism: A separate entity? Subst Alcohol Actions 4:129-136, 1983

8. Moss HB, Vanyukov M, Majumder PP, Kirisci L, Parter RE: Prepubertal sons of substance abusers: Influences of parental and familial substance on behavioral disposition, IQ, and school achievement. Addict Behav 20:345-358, 1995

9. Ozkaragoz TZ, Noble EP: Neuropsychological differences between sons of active alcoholic and non-alcoholic fathers. Alcohol Alcohol 30: $115-123,1995$

10. Schaeffer KW, Parsons OA, Yohman JR: Neuropsychological differences between male familial and nonfamilial alcoholics and nonalcoholics. Alcohol Clin Exp Res 8:347-351, 1984

11. Tarter RE, Hegedus AM, Goldstein G, Shelly C, Alterman AI: Adolescent sons of alcoholics: Neuropsychological and personality characteristics. Alcohol Clin Exp Res 8:216-221, 1984

12. Reed R, Grant I, Adams KM: Family history of alcoholism does not predict neuropsychological performance in alcoholics. Alcohol Clin Exp Res 11:340-344, 1987

13. Hesselbrock VM, Stabenau JR, Hesselbrock MN: Minimal brain dysfunction and neuropsychological test performance in offspring of alcoholics, in Galanter M (ed): Recent Developments in Alcoholism, vol 3. New York, Plenum Press, 1985, pp 65-82

14. Samson Y, Baron J-C, Feline A, Bories J, Crouzel C: Local cerebral glucose utilisation in chronic alcoholics: A positron tomography study. J Neurol Neurosurg Psychiatry 49:1165-1170, 1986

15. Gilman S, Adams K, Koeppe RA, Berent S, Kluin KJ, Modell JG, Kroll P, Brunberg JA: Cerebellar and frontal hypometabolism in alcoholic cerebellar degeneration studied with positron emission tomography. Ann Neurol 28:775-785, 1990

16. Mampunza S, Varbanck P, Verhas M, Martin P, Paternot J, Le Bon O, Kornreich C, Den Bulk A, Pelc I: Cerebral blood flow study in just detoxified alcoholic patients. A $99 \mathrm{~m}-\mathrm{Tc}-\mathrm{HMPAO}-\mathrm{SPECT}$ study. Acta Neurol Belg 95:164-169, 1995

17. Denays R, Tondeur M, Noel P, Ham HR: Bilateral cerebral mediofrontal hypoactivity in Tc-99m HMPAO-SPECT imaging. Clin Nucl Med 19:873-876, 1994

18. Volkow N, Wang GJ, Begleiter H, Hitzemann R, Pappas N, Burr G, Pascani K, Wong C, Fowler JS, Wolf AP: Regional metabolic response to lorazepam in subjects at risk for alcoholism. Alcohol Clin Exp Res $19: 510-516,1995$

19. Robins LN, Helzer J, Croughan J, Ratcliff KS: The NIMH Diagnostic Interview Schedule: Its history, characteristics and validity. Arch Gen Psychiatry 38:381-389, 1981

20. Mannuzza S, Fyer AJ, Endicott J: Family Informant Schedule and Criteria (FISC). New York, Anxiety Disorders Clinic, New York State Psychiatric Institute, 1985

21. Adams K, Grant I, Carlin A, Reed R: Self-reported alcohol consumption in four clinical groups. Am J Psychiatry 138:445-449, 1981

22. Grant I, Adams KM, Carlin A, Rennick P, Judd LL, Schooff K: The collaborative neuropsychological study of polydrug abusers. Arch Gen Psychiatry 35:1063-1074, 1978

23. Adams KM, Grant I: The influence of premorbid risk factors on neuropsychological performance in alcoholics. J Clin Exp Neuropsychol $8: 362-370,1986$

24. Heaton RK, Grant I, Matthews CG: Comprehensive norms for an extended Halstead-Reitan Battery. Odessa, FL, Psychological Assessment Resources, 1991

25. Hutchins GD, Holden JE, Koeppe RA, Halama JR, Gatley SJ, Nickles RJ: Alternative approach to single-scan estimation of cerebral glucose metabolic rate using glucose analogs, with particular application to ischemia. J Cereb Blood Flow Metab 4:35-40, 1984

26. Minoshima S, Koeppe RA, Mintun MA, Berger KL, Taylor SF, Frey KA, Kuhl DE: Automated detection of the intercommissural line for stereotactic localization of functional brain images. J Nucl Med 34:322329, 1993

27. Minoshima S, Koeppe RA, Frey KA, Kuhl DE: Anatomic standardization: Linear scaling and nonlinear warping of functional brain images. J Nucl Med 35:1528-1537, 1994

28. Adams KM, Gilman S, Koeppe RA, Kluin KJ, Brunberg JA, Dede D, Berent S, Kroll PD: Neuropsychological deficits are correlated with frontal hypometabolism in positron emission tomography studies of older alcoholic patients. Alcohol Clin Exp Res 17:205-210, 1993

29. Adams KM, Gilman S, Koeppe R, Kluin K, Junck L, Lohman M, Johnson-Greene D, Berent S, Dede D, Kroll P: Correlation of neuropsychological function with cerebral metabolic rate in subdivisions of the frontal lobes of older alcoholic patients measured with $\left[{ }^{18} \mathrm{~F}\right]$ fluorodeoxyglucose and positron emission tomography. Neuropsychology 9:275-280, 1995

30. Adams KM, Grant I, Brown GG: The use of covariance as a remedy for demographic group mismatch: Some sobering simulations. J Clin Exp Neuropsychol 7:445-462, 1985

31. Weifurt KP: Multivariate analysis of variance, in Grimm LG, Gold PR (eds): Reading and Understanding Multivariate Statistics. Washington, D.C., American Psychological Association, 1995, pp 245-267

32. Grant I, Adams KM, Reed R: Aging, abstinence and medical risk factors in the prediction of neuropsychological deficit among chronic alcoholics. Arch Gen Psychiatry 41:710-718, 1984

33. Volkow ND, Hitzemann RJ, Wang GJ, Fowler JS, Burr G, Pascani $\mathrm{K}$, Dewey S, Wolf AP: Decreased brain metabolism in neurologically intact healthy alcoholics. Am J Psychiatry 149:1016-1022, 1992

34. Wang GJ, Volkow ND, Hitzemann RJ, Oster ZH, Roque CT, Cestaro VL: Brain imaging of an alcoholic with MRI, SPECT and PET. Am J Physiol Imaging 7:194-198, 1992

35. Wang G-J, Volkow ND, Roque CT, Cestaro VL, Hitzemann RJ, Cantos EL, Levy AV, Dhawan AP: Functional importance of ventricular enlargement and cortical atrophy in healthy subjects and alcoholics as assessed with PET, MR imaging, and neuropsychologic testing. Radiology 186:59-65, 1993

36. Volkow ND, Wang GJ, Hitzemann RJ, Overall JE, Burr G, Wolf AP: Recovery of brain glucose metabolism in detoxified alcoholics. Am J Psychiatry 151:178-183, 1994

37. Jagust WJ: PET and SPECT imaging in cognitive disorders of aging and alcoholism, in Zakhari S, Witt E (eds): Imaging in Alcohol Research (NIAAA Research Monograph 21). Washington, D.C., U.S. Department of Health and Human Services, 1992, pp 333-358 
38. Shuckit MA: A 10-year follow of sons of alcoholics: Preliminary results. Alcohol Alcohol 1(Suppl.):147-149, 1991

39. Thompson WD, Orvaschel H, Prusoff BA, Kidd KK: An evaluation of the family history method for ascertaining psychiatric disorder. Arch Gen Psychiatry 39:53-58, 1982

40. Rice JP, Reich T, Bucholz KK, Neuman RJ, Fishman R, Rochberg N, Hesselbrock VM, Numberger JI Jr, Schuckit MA: Comparison of direct interview and family history diagnoses of alcohol dependence. Alcohol Clin Exp Res 19:1018-1023, 1995
41. Hill EM, Blow FC, Young JP, Singer KM: Family history of alcoholism and childhood adversity: Joint effects on alcohol consumption and dependence. Alcohol Clin Exp Res 18:1083-1090, 1994

42. Hesselbrock MN, Hesselbrock VM: Relationship of family history, antisocial personality disorder and personality traits in young men at risk for alcoholism. J Stud Alcohol 53:619-625, 1992

43. Satz P: Brain reserve capacity on symptom onset after brain injury: A formulation and review of evidence for threshold theory. Neuropsychology 7:273-295, 1993

\section{ANNOUNCEMENT}

Title:

Theme:

Location and dates:

Organizing secretariat:

Registration fees: 42nd International Institute on the Prevention and Treatment of Dependencies

The Changing Face of Addictive Behaviors Convergence and Divergence

Westin Dragonara Resort, St. Julians, Malta

August 30-September 4, 1998

ICAA

Case Postale 189

1001 Lausanne, Switzerland

tel.: (41 21) 3209865

fax: (41 21) 3209817

e-mail: icaa@pingnet.ch

website: http://www.icaa.ch

Before April 30, 1998:

Non-members of ICAA:

$\$ 550.00$

ICAA Full members:

$\$ 440.00$

ICAA Associate members:

$\$ 495.00$

After April 30, 1998:

Non-members of ICAA:

$\$ 650.00$

ICAA Full members:

$\$ 520.00$

ICAA Associate members:

$\$ 585.00$

Students (age limit 26 years):

$\$ 150.00$

Main topics:

Issues related to alcohol, tobacco, and other drug dependence, including gambling, prevention, treatment, research, policy.

Deadline for submitting abstracts: March 30, 1998

Languages of abstracts:

English and French

Deadline for submitting full papers:

If possible, March 30, 1998 or no later than October 30, 1998

Language of papers:

English and French

Publication:

Book of abstracts will be available to participants upon registration. Publication of proceedings to be determined.

Expected attendance:

$500-600$

Exhibition space:

Please contact organizing secretariat. 